\title{
ROMANIAN
}

NEUROSURGERY

\author{
Vol. XXXIV | No. 2 June 2020
}

\section{Long term study on the effects of microsurgical drezotomy for chronic pain control}

\author{
F. Aichaoui, \\ A. Khelifa, \\ M. Al-Zekri, \\ W. Bennabi, \\ S. Meyara, \\ A. Morsli
}




\title{
Long term study on the effects of microsurgical DREZotomy for chronic pain control
}

\author{
F. Aichaoui, A. Khelifa, M. Al-Zekri, W. Bennabi, \\ S. Meyara, A. Morsli
}

Neurosurgical Department of BEO University Hospital, Algiers, ALGERIA

\begin{abstract}
The DREZotomy (Dorsal Root Entry Zone tomy) is an analgesic procedure. The analgesic effect is evaluated on 30 patients with chronic pain resulting from respectively: brachial plexus avulsion (66.6\%), postherpetic pain (10\%), hyperspastic states $(6.6 \%)$, phantom pain $(6.6 \%)$, the pain in the stump $(6.6 \%)$, and spinal cord injuries (3.3\%). Pain intensity was evaluated using a visual analogue scale (VAS). At last evaluation, between 12 and 60 months, after DREZotomy, 93\% had a good or excellent global pain relief after surgery. According to the component types of pain, $9.6 \%$ of patients had good or excellent control of the paroxysmal pain, and $84 \%$ of the continuous pain. Kaplan-Meier prediction of lasting global pain control at 60 months of follow-up was calculated at $75.5 \%$. Comparison of the 2 corresponding Kaplan-Meier curves at long term, namely, pain control in $82.8 \%$ for the paroxysmal component and in $51.7 \%$ for the continuous component, showed a statistically significant difference $(P<0.0001)$. Functional effects are improved by more than $70 \%$ according to patients.
\end{abstract}

\section{INTRODUCTION}

Chronic pain is a major public health problem, causing disability and of considerable human suffering. Depressive states are frequently associated with it; without counting the health costs it generates. There are, however, situations where conservative methods such as conventional drugs and psychotherapies are not effective and where the use of "lesional" neurosurgical management can provide an effective solution. This is the case for certain microsurgical techniques including DREZotomy (DREZ: Dorsal Root Entry Zone). This technique consists in interrupting the so-called nociceptive fibers and destroying by coagulation the hyperactive neurons located in the dorsal horn, corresponding to the area of pain, respecting the other fibers. It has been shown to be effective in some cases of chronic pain [2-5, 8, 9].

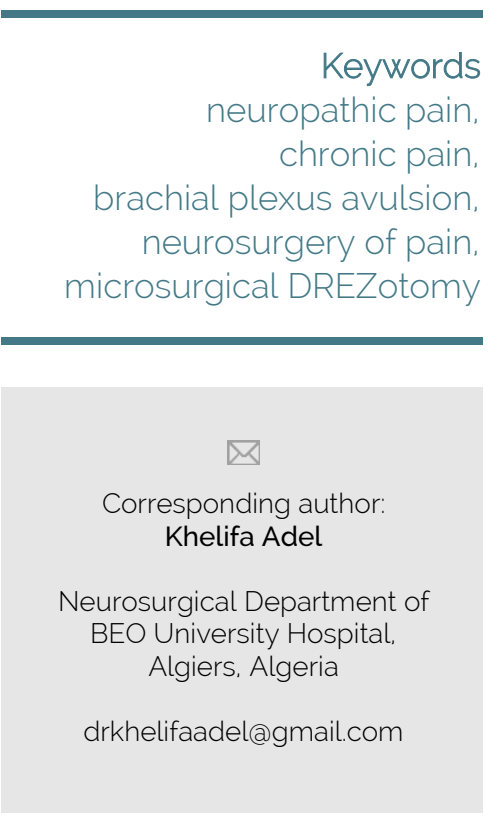

Copyright and usage. This is an Open Access article distributed under the terms of the Creative Commons Attribution Non-Commercial No Derivatives License (https://creativecommons org/licenses/by-nc-nd/4.0/) which permits noncommercial re-use, distribution, and reproduction in any medium, provided the original work is unaltered and is properly cited.

The written permission of the Romanian Society of Neurosurgery must be obtained for commercial re-use or in order to create a derivative work.

ISSN online 2344-4959 (C) Romanian Society of Neurosurgery

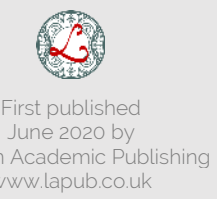




\section{Methods}

We conducted a prospective study of 30 patients who underwent microsurgical DREZotomy for chronic pain resistant to medical treatment. This work was carried out between July 2007 and January 2015. Our series included 2 women and 28 men, who had an average age of 46 years with extreme ages of 25 and 79 years. All patients had a detailed clinical assessment including the characteristics of their pain, its intensity using the Visual Analog Scale (VAS), as well as an assessment of the psychological impact of the pain. Imaging, represented by CT scan and / or spinal MRI, was performed before the surgery to assess the extent of the lesions.

\section{ETIOLOGIES}

The chronic pain that affected our patients was caused by sequelae of brachial plexus avulsion (BPA) in 20 cases (66.6\%) (figure 1), postherpetic neuralgia in 3 cases (10\%), stump pain in 2 cases $(6.6 \%)$, the phantom limb in 2 cases (6.6\%), spasticity in 2 cases $(6.6 \%)$ and one case (3.3\%) of spinal cord injury.

\section{PAIN DESCRIPTION}

In our study, more than half of the patients (56.7\%) experienced pain initially, and $33.3 \%$ two months after the onset of the lesions. The time between onset of pain and surgery is on average $5 \pm 1$ year. Three patients had a DN4 (Douleur Neuropathique en 4 Questions, French for neuropathic pain in 4 questions), lower than 3 , including 2 with stump pain and one patient with phantom limb pain. In fact, during the interrogation, we noted in 25 patients (83.3\%) the presence of tingling. These latter involved 18 patients with BPA (90\%), all patients with postherpetic neuralgia, spinal cord injury and a patient with phantom limb pain (50\%). Numbness was reported in 3 patients (10\%) including two patients with BPA (10\%) and a patient with spasticity (50\%). Dysesthesia was present in one patient who has BPA. Analogous visual scale (VAS) of our patients was initially on average $9.20 \pm 1.06$ with extreme values of 7 and 10 . Two categories of pain were noted, in particular electrical shooting-like paroxysmal pain, and the continuous pain realizing a painful background most often a burning type. The two components combined were present in $83 \%$ of patients. The paroxysmal and background components alone interested $6.7 \%$ and $10 \%$ of the patients, respectively. In the BPA, the pain concerned
C6 and C7 dermatomes in all cases, and C8 and T1 dermatomes, in $95 \%$ and $90 \%$ of cases, respectively. For stump pain, the dermatomes affected by the pain range from $\mathrm{C} 6$ to $\mathrm{T} 1$. For the phantom limb, the pain areas extend from C5 to T1. In the three patients with postherpetic neuralgia, the dermatomes concerned range from $\mathrm{C} 7$ to $\mathrm{T} 1$ and from $\mathrm{T} 3$ to $\mathrm{T} 8$ at a frequency of $33.33 \%$ of cases for each one, associated in cases with allodynia. In the patient who suffered from chronic pain due to spinal cord injury, the dermatomes involved range from L2 to S2. As for patients suffering from spastic pain, the dermatomes concerned are $L 1$ and $L 2$ but also L4, L5 and S1. Whatever the causal etiology of chronic pain, there is a noticeable impact on several aspects of life, whether individual, social or professional.

\section{MedicAl TREATMENT}

All of our patients received simultaneous treatment with WHO class I and II anticonvulsants, tricyclics and analgesics. However, we note that 5 (16.6\%) of our patients took at least occasional WHO class III analgesics during their previous management. Two of our three patients with postherpetic neuralgia used topical lidocaine as a patch in the allodynic areas. Although the duration of treatment was 5 years \pm 1 year, there was no reported improvement.

\section{SURGICAL MANAGEMENT}

Microsurgical DREZotomy was performed under general anesthesia. The patients were placed in the prone position. The laminectomy was homolateral to the corresponding painful dermatomes and bilateral when the symptomatology concerned both sides. After opening the dura mater, micro-incisions under an operating microscope were performed at the spinal cord dorsolateral sulcus at the entrance of the posterior roots. The incision was of $2 \mathrm{~mm}$ deep at an angle of $35^{\circ}$ anteriorly and medially when it was the cervical and thoracic levels and $45^{\circ}$ when it was the lumbar region. These incisions were followed by lowintensity micro-coagulations (figures 2 and 3).

\section{RESULTS}

The effects of DREZotomy on pain are evaluated when the patient is discharged from the hospital, in average, 15 days after surgery, but also evaluated at 3 months and at long term (beyond 6 months). Whatever the etiology, the results of DREZotomy are mainly excellent for 26 patients (86.6\%) at discharge, 
for 25 patients (86.2\%) at 3 months, and for 20 patients (68.9\%) in the long term; the good results interested 4 patients (13.3\%) at discharge, 4 patients (13.7\%) at 3 months and 7 patients (24.1\%) in the long term; poor results are rare and concerned only 2 patients (6.8\%) in the long term (Figure 4). The longterm overall pain control defined by excellent to good results is studied by the KAPLAN-MEIER curve; this one shows $75.7 \%$ pain control over a 60 month follow-up period (Figure 5). In our study, the results are excellent on allodynia, especially in patients with postherpetic neuralgia. The correlation between the number of painful dermatomes and the results of microsurgical DREZotomy is statistically significant; the fewer the number of dermatomes, the more excellent the results of the DREZotomy ( $p=0.0093$ ). The control of the pain components defined by excellent and good results is analyzed using the KAPLAN-MEIER curve; this one shows that the control of the paroxysmal and continuous components is estimated respectively at $82.8 \%$ and $51.7 \%$ over a period of 60 months (Figures 6 and 7). This analysis demonstrates the effectiveness of the technique on the various components of pain with a predilection on the paroxysmal component compared to the continuous component ( $p<0.0001)$. Surgical DREZotomy improves the quality of life in all its aspects and whatever the etiology. This improvement is statistically significant in all cases ( $p$ $=0.00000$ ). There is an average improvement of $83 \pm$ $15 \%$ in daily activity, $79 \pm 14 \%$ in walking, $85 \pm 14 \%$ in the mood, $77 \pm 15 \%$ in social relationships, and $85 \pm$ $14 \%$ in sleep quality. The reduction in the doses of the drugs was performed gradually until stopping, in 3-4 weeks. Analgesic treatment at low doses was continued in 6 patients. Complications are generally few and quickly resolve; limited essentially to neck pain in $15.4 \%$ of cases, and in much rarer cases there was: CSF fistula in $3.3 \%$ of cases, ataxia, tactile hypoesthesia, transient or permanent arthrokinesthesia, transient dysthesia, and mild motor disorder in $3.7 \%$ of cases for each of these complications. We regret a death of one patient which occurred during hospitalization caused by a pulmonary embolism.

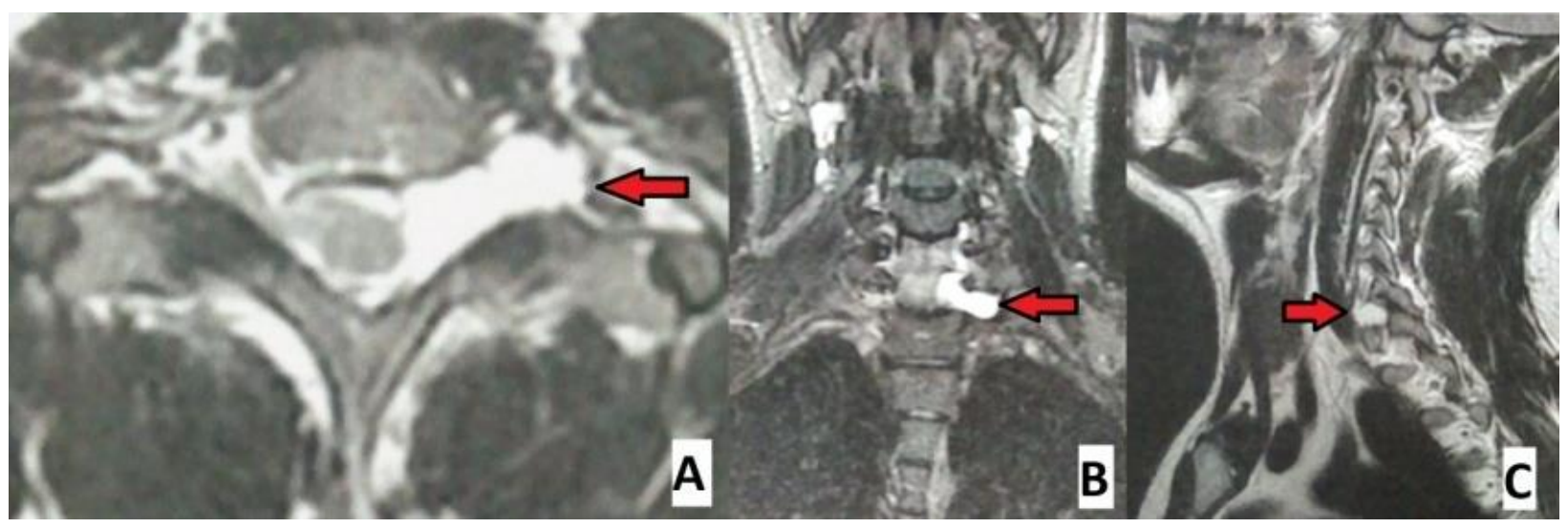

Figure 1. Preoperative cervical spine MRI in T2 weighted images, in patient suffering from brachial plexus avulsion pain; $A$ : axial slide, B: coronal slide, C: sagittal slide; the arrow shows a pseudoméningocèle characteristic lesion of brachial plexus avulsion.

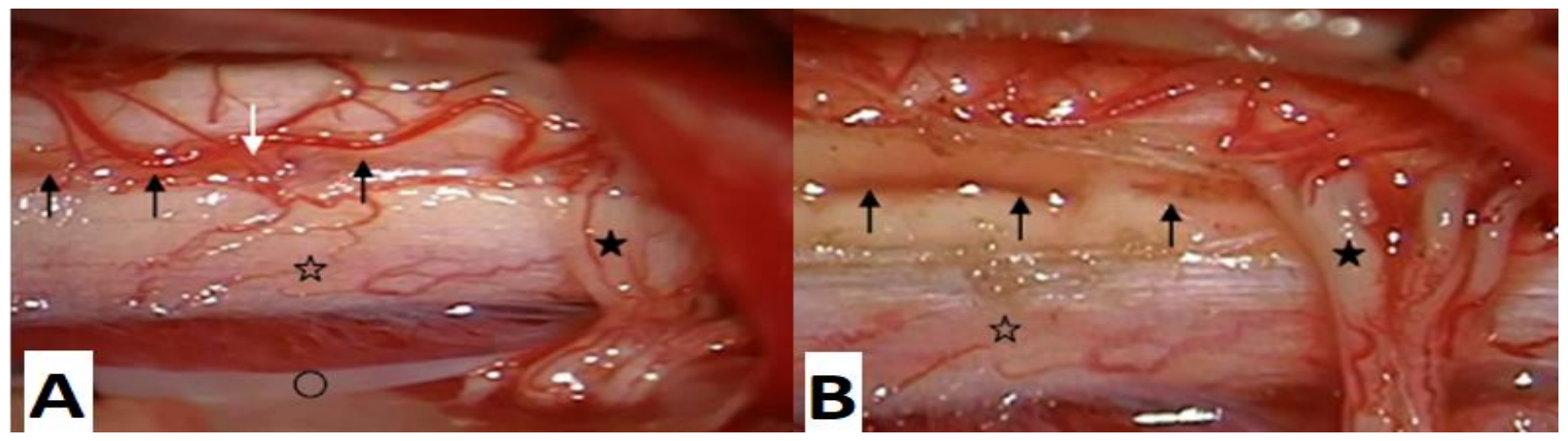

Figure 2. Per operative pictures in patient suffering from brachial plexus avulsion; A: before DREZotomy, B: after DREZotomy. The 
black arrows show the DREZotomy zone for an avulsed C6 root, the white arrows show micro blood vessels entering the DREZ zone, the full star shows the $\mathrm{C} 5$ root, the empty star shows the spinal cord, and the ring the denticulate ligaments.

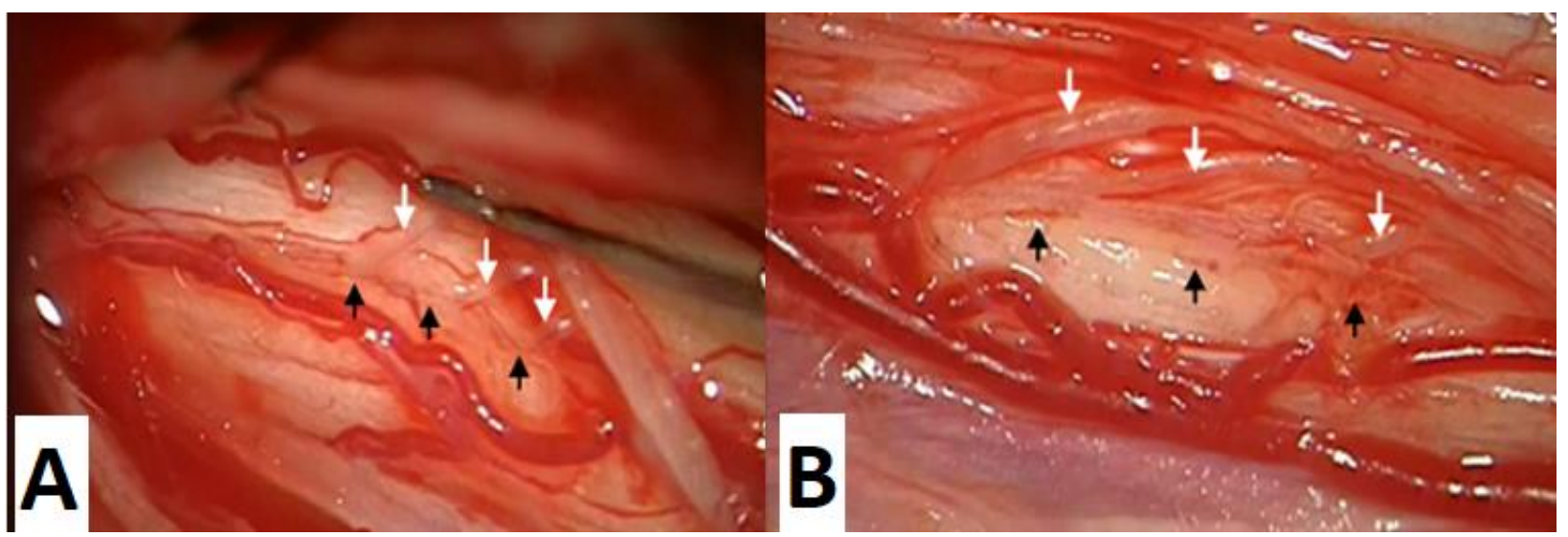

Figure 3. Per operative pictures in a patient suffering from postherpetic neuralgia; A: before DREZotomy, B: after DREZotomy. The black arrows show the DREZotomy zone, the white arrows show atrophied C7 root.

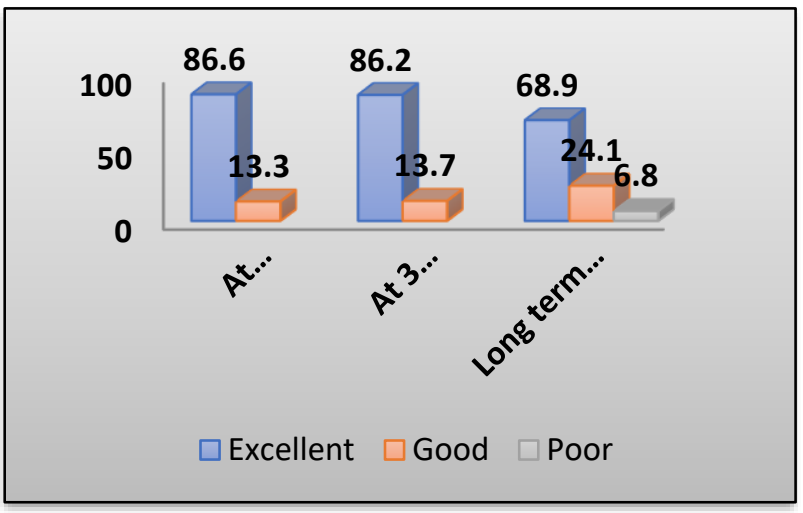

Figure 4. Good to excellent results of DREZotomy on overall pain at discharge, at 3 months and in the long term, all etiologies taken together (Excellent: Improvement greater than 75\%; good: Improvement between $75 \%$ and $50 \%$, and poor improvement less than $50 \%)$.

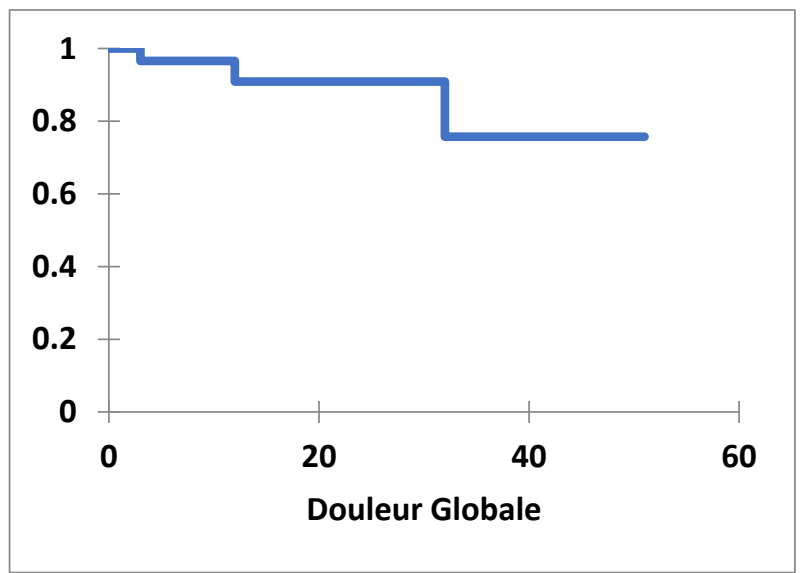

Figure 5. Kaplan Meier curve describing in percentage the longterm overall pain control (excellent to good). Pain control is estimated at $75.7 \%$ over a 60 -month follow-up period. Excellent: Improvement greater than 75\%; Good: Improvement between $75 \%$ and $50 \%$.

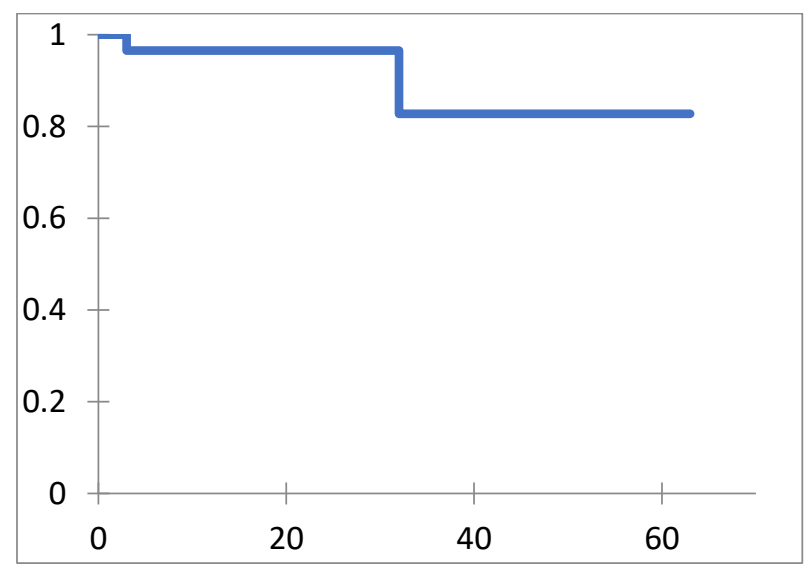

Figure 6. The Kaplan Meier curve describing in percentage the control of the paroxysmal component of pain (excellent to good) in the long term. Pain control is estimated at $82.8 \%$ over a period of 60 months. Excellent: Improvement greater than 75\%; Good: Improvement between $75 \%$ and $50 \%$.

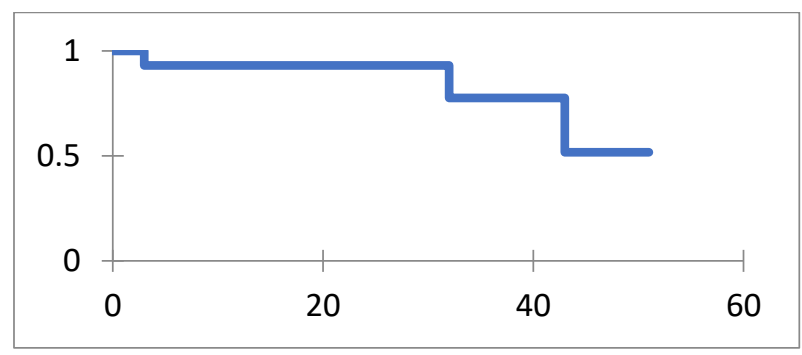

Figure 7. The Kaplan Meier curve describing in percentage the control of the continuous component of pain (excellent to good) in the long term. Pain control is estimated at $51.7 \%$ over 
a period of 60 months. Excellent: Improvement greater than 75\%; Good: Improvement between $75 \%$ and $50 \%$.

\section{DISCUSSION}

We believe that the effectiveness of DREZotomy on pain reinforces the hypothesis that the dorsal horn plays a main role in the genesis of pain [4]. Guenot et al report the appearance of hyperactive neurons after the experimental rhizotomy performed in animals [13]. DREZotomy significantly suppresses autotomy behavior in animals that have undergone rhizotomy. Neuron hyperactivity has also been recorded using microelectrodes implanted in the dorsal horn during the DREZotomy procedure for BPA pain $[12,14,16]$. The fact that the paroxysmal component is often reduced by DREZotomy, suggests that its origin predominates in the dorsal horn. Central sensibilisation by the phenomenon of denervation cannot in itself explain the mechanism generating pain within the dorsal horn. Like other authors, we have frequently observed intraoperatively, the presence of hemosiderin deposits, microcavitations and gliotic tissue within the gray matter of the dorsal horn in the cases of BPA and spinal cord injury $[4,10,17]$. These lesions can cause a change in normal activity within this region and consequently cause dysfunction of the pain pathways at the spinal or cerebral level [16]. However, it is quite clear that not all pain-generating centers are located at the dorsal horn. As for the mechanism of the continuous component, dominated by the burning sensation which is less influenced by DREZotomy than the paroxysmal component, it remains less clear; however, several hypotheses can be put forward. BPA causes more or less extensive necrosis of cells belonging to the dorsal horn that participate in the spinothalamic tract ascending pathway, as well as in the case of spinal cord trauma. This results in some degree of spino-reticulo-thalamic pain responsible of the continuous component [4]. The mechanisms of postherpetic neuralgia are similar to the abovementioned mechanisms; the presence of the varicella zoster virus in the sensory neurons of the dorsal ganglion [1] causes inflammation and cell destruction within it $[7,15,23]$. The inflammatory process extends along the sensitive fibers to the dorsal horn, causing lesions similar to those observed in the BPA [3], which explains the beneficial effect of DREZotomy on the two components, in particular the component paroxysmal as well as allodynia. DREZotomy acts by suppressing the collaterals of the $A \beta$ fibers which are oriented towards the nociceptive layers of the dorsal horn. Several hypotheses are suggested in the stump pain and the phantom limb pain. In fact, the loss of the afferent influx from the periphery leads to irritation of the neurons of the dorsal horn and their hyperexcitability and reduction of inhibitory processes $[11,18,25]$. This gives the DREZ area a therapeutic interest. According to the series, paraplegic pain is mostly secondary to the conus medullaris lesion which often accompanies spinal trauma [21], probably in relation with the site corresponding to the thoraco-lumbar junction which is exposed to frequently to fractures. The thoracolumbar junction corresponds to numerous spinal segments condensed on a small poorly vascularized (Adamkiewicz artery) explaining their concomitant involvement during the trauma. The mechanism of spastic pain may be linked to painful spasms, painful contracture and neuropathic pain [21]; which occurs in multiple sclerosis [8,9], and spinal cord injury [10]. This neuropathic disorder is secondary to a demyelization of the spino-thalamic tract $[6,24]$ and the posterior horn where the paroxysmal and continuous components are usually present. The beneficial effect of DREZotomy, on the various components of pain in particular the paroxysmal component was obtained by interrupting the myotatic fibers (monosynaptics), and the nociceptive fibers (polysynaptics), thus depriving the somatosensitive relays of the dorsal horn of all excitatory afferents [22].

\section{CONCLUSIONS}

DREZotomy has a satisfactory operating risk / benefit ratio with few side effects. It is suitable for chronic refractory pain especially BPA and spinal cord injury. It significantly attenuates chronic pain in its paroxysmal but also continuous components with supremacy for paroxysmal pain, including in allodynic phenomena.

CONFLICT OF INTEREST

None

\section{REFERENCES}

1. Ada Delaney, Lesley A. Colvin, Marie T. Fallon, Robert G. Dalziel, Rory Mitchell, and Susan M. Fleetwood-Walker. Postherpetic Neuralgia: From Preclinical Models to the 
Clinic. Neurotherapeutics: The Journal of the American Society for Experimental NeuroTherapeutics. October 2009. Vol. 6, 630-637.

2. Adam F. et le Bars D. Voies de la douleur. In: Martin C., Riou B. et Vallet B. (2006). Physiologie humaine appliquée. Arnette, Rueil-Malmaison, 845-857.

3. Allan H. Friedman, Blaine S. Nashold, AND Janice Ovelmen-LevitT. Dorsal root entry zone lesions for the treatment of post-herpetic neuralgia. J Neurosurg 60:1258-1262, 1984

4. Aichaoui F, Mertens $P$, Sindou M. Dorsal root entry zone lesioning for pain after brachial plexus avulsion: Results with special emphasis on differential effects on the paroxysmal versus the continuous components. A prospective study in a 29-patient consecutive series. PAIN_ 152 (2011) 1923-1930

5. Han ZS, Zhang ET, Craig AD. Nociceptive and thermoreceptive lamina I neurons are anatomically distinct. Nat Neurosci $1998 ; 1: 218-25$.).

6. Dahm.P.O, Nitescu.P.V, Appelgren.L.K and Curelaru.L. Long-term intrathecal (i.t.) infusion of bupivacaine relieved intractable pain and spasticity in a patient with multiple sclerosis. European Journal of Pain (1998) 2: 8185.

7. D'Hardemare Vincent, Margot-Dclot Anne, Bruxelle Jean, Bachelart Maximillien, Thiébaut Jean-Baptiste.Chirurgie de la douleur de la lésion à la neuromodulation. Springer 2014; 33 :374-387.

8. Devor M. Sodium channels and mechanisms of neuropathic pain. J Pain 2006;7(Suppl. 1): 3-12.

9. Dickenson A. The inhibitory effects of thalamic stimulation of the spinal transmission of nociceptive information on the rat) (Gerhart KD, Yezierski RP, Fang ZR, Willis WD. Inhibition of primate spinothalamic tract neurons by stimulation in ventral posterior lateral (VPLC) thalamic nucleus: possible mechanisms. J Neurophysiol 1983; 49 :406-23.

10. Dreval ON. Ultrasonic DREZ-operations for treatment of pain due to brachial plexus avulsion. Acta Neurochir 1993;122:76-81.

11. Flor H. Phantom-limb pain: characteristics, causes, and treatment. Lancet Neurol 2002;1:182 9.

12. Guenot M, Bullier J, Rospars JP, Lansky P, Mertens $P$, Sindou M. Single-unit analysis of the spinal dorsal horn in patients with neuropathic pain. J Clin Neurophysiol 2003;20:143-50.
13. Guenot $M$, Bullier J, Sindou M. Clinical and electrophysiological expression of deafferentation pain alleviated by dorsal root entry zone lesions in rats. J Neurosurg 2002;97:1402-9.

14. Guenot M, Hupe JM, Mertens P, Ainsworth A, Bullier J, Sindou M. A new type of microelectrode for obtaining unitary recordings in the human spinal cord. J Neurosurg Spine 1999;91:25-32.

15. Hökfelt $T$, Zhang $X$, Wiesenfeld-Hallin Z. Messenger plasticity in primary sensory neurons following axotomy and its functional implications. Trends Neurosci 1994;17:22-30.

16. Jeanmonod D, Sindou M, Magnin M, Boudet M. Intraoperative unit recordings in the human dorsal horn with a simplified floating microelectrode. Electroencephalogr Clin Neurophysiol 1989;72:450-4.

17. Kandel El, Ogleznev KIA, Dreval ON. Destruktsiia vkhodnoi zony zadnykh koreshkov kak metod lecheniia khronicheskoi boli pri traumaticheskikh povrezhdeniiakh plechevnogo spleteniia. Zh Vopr Neirokhir Im N N Burdenko 1987;6:20-7.

18. Kerr, 1975a. Snyder, 1977 ; livre ablative.

19. Lazorthes Y, Sallerin-Caute B, Verdie JC, et al. Chronic intrathecal Baclofen administration for control of severe spasticity. J Neurosurg. 1990; 72:393-402.

20. Penn RD, Kroin JS. Continuous intrathecal baclofen for severe spasticity. Lancet 2:125-127, 1985) (Lazorthes $Y$, Sallerin-Caute B, Verdie JC, et al: Chronic intrathecal Baclofen administration for control of severe spasticity. J Neurosurg 72:393-402, 1990.

21. Sindou Marc P., and Mertens Patrick. Surgery in the Dorsal Root Entry Zone for Spasticity in Adults. Operative Technique in Neurosurgery.2005. Elsevier. Inc.

22. Sindou.M, E Blondet, E Emery, and $\mathrm{P}$ Mertens. Microsurgical lesioning in the dorsal root entry zone for pain due to brachial plexus avulsion : a prospective series of 55 patients. J Neurosurg 102 : 1018-1028. 2005.

23. Smith MT, Edwards RR, McCann UD, Haythornthwaite JA. The effects of sleep deprivation on pain inhibition and spontaneous pain in women. Sleep 2007;30:494-505.

24. Thomas RJ. Excitatory amino acids in health and disease. J Am Geriatr Soc 1995; 43:1279-89.

25. Woolf CJ, Ma Q. Nociceptors- Noxious stimulus detectors. Neuron $200 ; 55:$ 353-64. 